\title{
Occupational Health and Safety Management Systems: Institutional and Regulatory Frameworks in Zimbabwe
}

\author{
Hope Taderera \\ Department of Political and Administrative Studies, University of Zimbabwe \\ Mount Pleasant, Harare, Zimbabwe \\ Tel: +263774 $493522 \quad$ E-mail: htaderera@gmail.com
}

Accepted: August 27, 2012 Published: October 29, 2012

Doi:10.5296/ijhrs.v2i4.2149

URL: http://dx.doi.org/10.5296/ijhrs.v2i4.2149

\begin{abstract}
The discussion focuses on the Occupational Health and Safety Management System which was initiated by the International Labour Organization to facilitate the formulation, implementation and evaluation of occupational health and safety interventions at a national policy, sector and organizational level in all countries. It also focuses on Zimbabwe's occupational health and safety policy, regulatory and institutional framework. The ILO's OSH-MS 2001 was developed to provide a unique international model, compatible with other management system standards and guides, towards promoting occupational health and safety in a systematic manner. In Zimbabwe, occupational health and safety laws that are applicable to all employers and employees across sectors are enshrined within the Labour Act, Chapter 28.01, and the National Social Security Authority's Accident Prevention Workers Compensation Scheme Notice No. 68 of 1990. Occupational health and safety management in Zimbabwe is pursued through the International Labour Organization's Zimbabwe Office, the Ministry of Public Service, Labour and Social Welfare, the National Social Security Authority, and the Zimbabwe Occupational Health and Safety Council, which comprises government, employers and labour unions. It was recommended that Zimbabwe fully adopts the OHS-MS in all sectors, industries and organizations in an adaptive manner. The study also recommended systematic capacity building at a national, sectoral, industrial and organizational level to enhance effective, efficient and adaptive implementation of this tool, and continuous interaction and engagement between the ILO, Ministry of Labour and Social Welfare, EMCOZ, ZCTU and ZFTU for the realization of the highest standards of occupational health and safety in Zimbabwe.
\end{abstract}


Keywords: Occupational, Health, Safety, Management, System, Framework, Zimbabwe

\section{Introduction}

Occupational Safety and Health (OSH) is a discipline dealing with the prevention of work related injuries and diseases, and the protection and promotion of the health of workers. It aims at the improvement of working conditions and environment. Occupational health entails the promotion and maintenance of the highest degree of physical and mental health and social well-being of workers in all occupations. In this context, the anticipation, recognition, evaluation and control of hazards arising in or from the workplace that could impair the health and well being of workers are the fundamental principles of the process governing occupational risk assessment and management. The International Labour Organization (ILO) formulated an Occupational Safety and Health Management System (OHS-MS) to facilitate the formulation, implementation and evaluation of interventions at a national policy, sector and organizational level in all countries. This discussion is on the policy ingredients associated with this tool. It also focuses on Zimbabwe's occupational health and safety policy, regulatory and institutional framework, a platform through which the OSH-MS may be implemented.

\section{ILO Guidelines on OSH Management Systems (ILO-OSH 2001)}

The ILO-OSH 2001 was developed to provide a unique international model, compatible with other management system standards and guides, towards promoting occupational health and safety (ILO, 2011; 2010). In the ILO document ILO-OSH 2001, Guidelines on Occupational Safety and Health Management Systems, the basic components of this system include policy, organizing, planning and Implementation, evaluation, and action for Improvement. Although other occupational health and safety models use different terminology, the process and workflow for occupational health and safety management systems is always the same. It entails the establishment, within policy statements, of what the requirements are for the organization in terms of resources, defining management commitment and defining occupational safety and health targets. It also involves determining how the organization is structured, where the responsibilities and accountabilities are defined, who reports to who and the allocation of responsibilities. Planning and Implementation are also involved in this management system.

This involves determining the legislation and standards which apply to an organization, what OSH objectives are defined and how these are reviewed, hazard prevention and the assessment, and management of risk procedures and processes. The system also involves determining how the occupational safety and health intervention performance are measured and assessed, the processes for the reporting of accidents and incidents and for the investigation of accidents and the internal and external audit processes in place to review the system. This will lay a platform upon which action for improvement may be pursued, through determining how the preventative and corrective actions are managed and the processes in place to ensure the continual improvement process. The ILO-OSH 2001 is not legally binding and not intended to replace national laws, regulations and accepted standards. It reflects ILO values such as tripartism and relevant international standards including the Occupational Safety and Health 
Convention, 1981 (No. 155) and the Occupational Health Services Convention, 1985 (No. 161). The ILO Guidelines encourage the integration of the OSH Management System with other management systems and state that occupational safety and health should be an integral part of organizational management. The application of the management systems approach at the national level proposes an integrated operational mechanism for continual improvement comprising a national OSH policy formulated, implemented and periodically reviewed by the competent authority in consultation with the most representative organizations of employers and workers. It also comprises a national OSH system which contains the infrastructure to implement the national policy, and national programmes and coordinate the national regulatory, technical and promotional, actions related to OSH. The OSH-MS also involves a national OSH programme defining national objectives relevant to OSH in a predetermined time frame, establishing priorities and means of action developed through an analysis of the national OSH situation as summarized by a National OSH Profile. It also includes a mechanism to review the outcomes of the national programme with a view to assessing progress and defining new objectives and actions for the next cycle (Ibid). The guidelines provide guidance for implementation on two levels at the national and organizational.

\section{National Occupational Safety and Health Management System Framework}

At the national level, the ILO Guidelines provide for the establishment of a national framework for Occupational Safety and Health (OSH) Management Systems (MS), preferably supported by national policies, laws and regulations (ILO, 2011). Action at national level includes the nomination of competent institution(s) for OSH-MS, the formulation of a coherent national policy and the establishment of a framework for an effective national application of ILO-OSH 2001, either by means of its direct implementation in organizations or its adaptation to national conditions and practice (by national guidelines), and specific needs of organizations in accordance with their size and nature of activities (by tailored guidelines) (Ibid). The National Policy for OSH-MS should be formulated by competent institution(s) in consultation with employers' and workers' organizations, and should consider the promotion of OSH-MS as part of overall management, and the promotion of voluntary arrangements for systematic OSH improvement. It should also consider avoiding unnecessary bureaucracy, administration and costs, and support by the labour inspectorate, safety and health and other related services. The functions and responsibilities of implementing institutions should be clearly defined as well. The diagram below describes the elements of the national framework for OSH-MS, and shows the different ways through which ILO-OSH 2001 may be implemented within a member state. 
Table1: Elements of the National Framework for OSH-MS

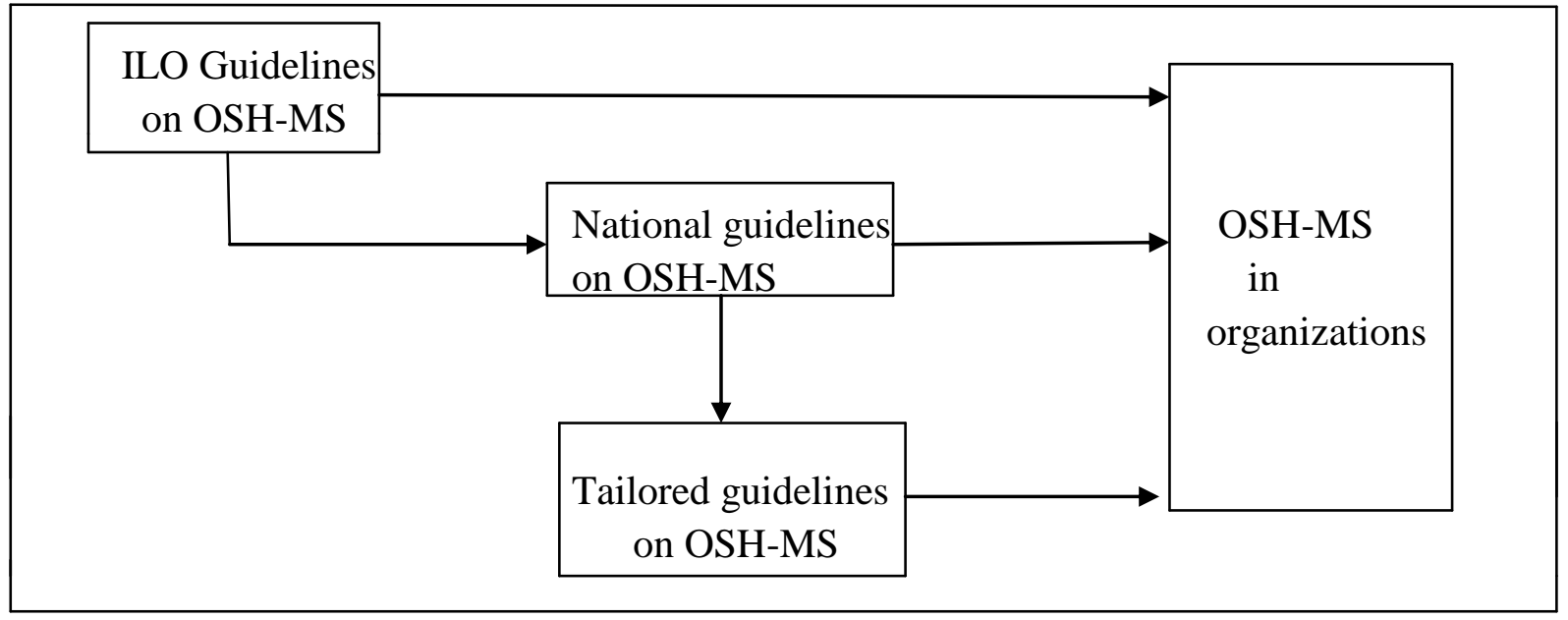

(Source: ILO; 2010, 16)

\section{The Occupational Safety and Health Management System in the Organization}

ILO-OSH 2001 also deals with the occupational safety and health management system at the organizational level, in which emphasis is that compliance to national laws and regulations are the responsibility of the employer (Alli, 2001). The Guidelines encourage the integration of OSH-MS elements into overall policy and management arrangements, and emphasise the importance that at organizational level, OSH should be a line management responsibility, and should not be seen as a task for OSH departments and/or specialists. The OSH management system in the organization has five main sections which follow the internationally accepted Demming Cycle of Plan-Do-Check-Act, which is the basis to the system approach to management. These sections include Policy, Organizing, Planning and implementation, Evaluation and Action for improvement Policy contains the elements of OSH Policy and Worker Participation. It is the basis of the OSH-MS as it sets the direction for the organization to follow. Organizing contains the elements of responsibility and accountability, competence and training, documentation and communication. It makes sure that the management structure is in place, as well as the necessary responsibilities allocated for delivering the OSH policy (Ibid). Planning and implementation contains the elements of initial review, system planning, development and implementation, OSH objectives and hazard prevention. Through the initial review, it shows where the organization stands concerning $\mathrm{OSH}$, and uses this as the baseline to implement the OSH policy. Evaluation contains the elements of performance monitoring and measurement, investigation of work related injuries, ill-health, diseases and incidents, audit and management review. It shows how the OSH management system functions and identifies any weaknesses that need improvement. It includes the very important element of auditing, which should be undertaken for each stage, in which persons independent of the activity being audited should conduct the audits (ILO, 2011, 2010). Action for improvement includes the elements of preventive and corrective 
action and continual improvement. It implements the necessary preventive and corrective actions identified by the evaluation and audits carried out. It also emphasizes the need for continual improvement of OSH performance through the constant development of policies, systems and techniques to prevent and control work-related injuries, ill health, diseases and incidents (Ibid). The main sections and their elements of the OSH-MS at the organization are illustrated in the diagram below:

\subsection{Elements of the OSH-MS at an Organizational Level}

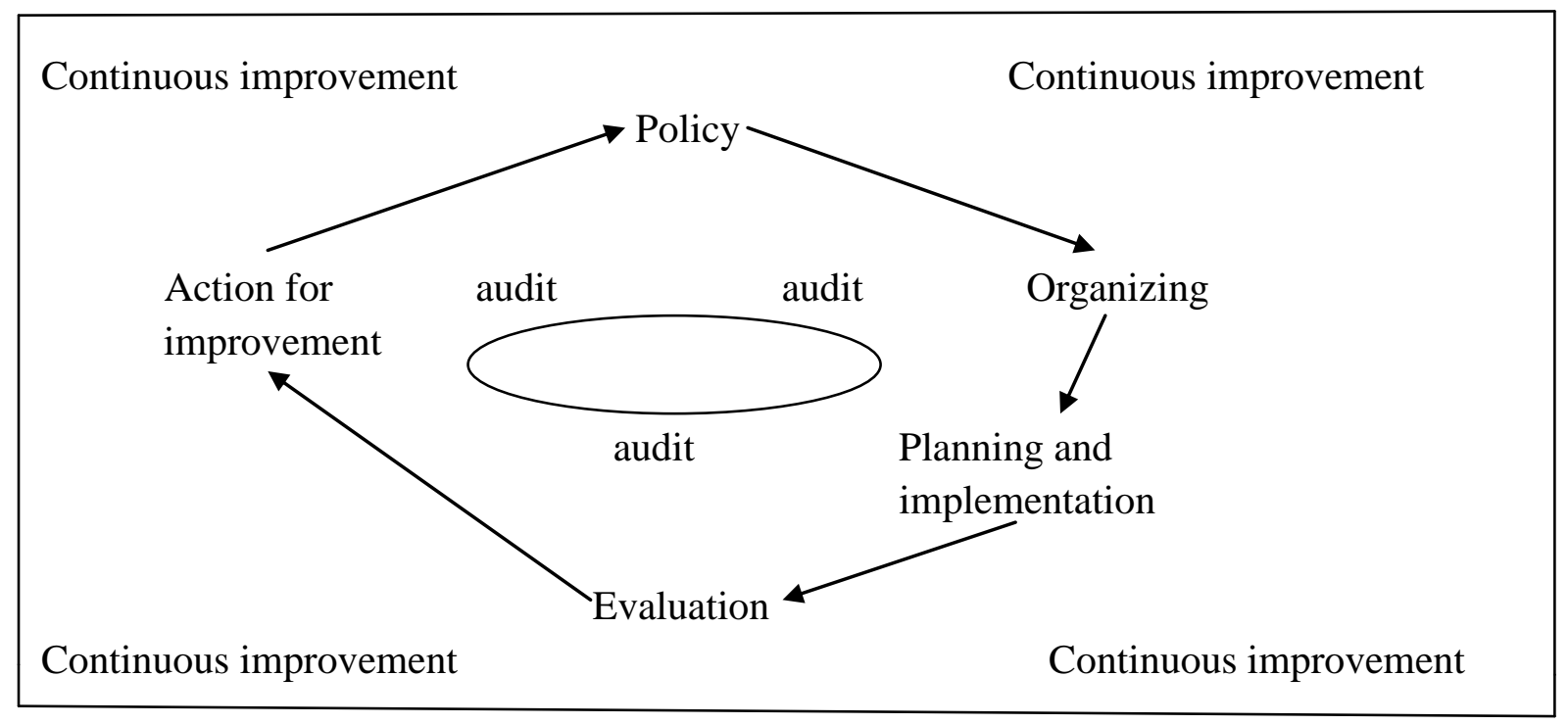

(Source: ILO; 2010, 17)

\section{Policy}

\subsection{Occupational Safety and Health Policy}

The employer, in consultation with workers and their representatives, should set out in writing an OSH policy, which should be specific to the organization and appropriate to its size and the nature of its activities (ILO, 2010). The OSH policy should include, as a minimum, principles and objectives to which the organization is committed. These may include protecting the safety and health of all members of the organization by preventing work-related injuries, ill health, diseases and incidents. It should comply with relevant OSH national laws and regulations, voluntary programmes, collective agreements on OSH and other requirements to which the organization subscribes, ensuring that workers and their representatives are consulted and encouraged to participate actively in all elements of the OSH-MS and continually improving the performance of the OSH-MS (Ibid). The OSH-MS should be compatible with or integrated in other management systems in the organization.

\subsection{Worker Participation}

Worker participation is an essential element of the OSH-MS in the organization. The employer should ensure that workers and their safety and health representatives are consulted, informed and trained on all aspects of OSH, including emergency arrangements, associated with their work (Alli, 2001; ILO, 2010). Arrangements should be made by the 
employer for workers and their safety and health representatives to have the time and resources to participate actively in the processes of organizing, planning and implementation, evaluation and action for the improvement of the OSH-MS. The employer should also ensure, as appropriate, the establishment and efficient functioning of a safety and health committee and the recognition of workers' safety and health representatives, in accordance with national laws and practice (Ibid).

\section{Organizing}

\subsection{Responsibility and accountability}

The employer should have overall responsibility for the protection of workers' safety and health, and provide leadership for OSH activities in the organization (ILO, 2001). Allocation of responsibility, accountability and authority for the development, implementation and performance of the OSH management system and the achievement of the relevant OSH objectives should be made by the employer. Structures and processes should be established which ensure that OSH is a line-management responsibility which is known and accepted at all levels, and define and communicate to the members of the organization the responsibility. These structures and processes should also ensure accountability and authority of persons who identify, evaluate or control OSH hazards and risks, provide effective supervision, as necessary, to ensure the protection of workers' safety and health (Ibid). They should also promote cooperation and communication among members of the organization, including workers and their representatives, to implement the elements of the organization's OSH-MS, and fulfil the principles of OSH management systems contained in relevant national guidelines, tailored guidelines or voluntary programmes, as appropriate, to which the organization subscribes. There is a need to establish and implement a clear OSH policy and measurable objectives, establish effective arrangements to identify and eliminate or control work-related hazards and risks, and promote health at work. Equally important is the need to establish prevention and health promotion programmes, ensure effective arrangements for the full participation of workers and their representatives in the fulfilment of the OSH policy. These is also need to provide appropriate resources to ensure that persons responsible for $\mathrm{OSH}$, including the safety and health committee, can perform their functions properly and to ensure effective arrangements for the full participation of workers and their representatives in safety and health committees, where they exist (ILO, 2011; ILO, 2010). A person or persons at the senior management level should be appointed, where appropriate, with responsibility, accountability and authority for the development, implementation, periodic review, and evaluation and reporting of the OSH management system.

\subsection{Competence and training}

The necessary OSH competence requirements should be defined by the employer, and arrangements established and maintained to ensure that all persons are competent to carry out the safety and health aspects of their duties and responsibilities. The employer should have, or should have access to, sufficient OSH competence to identify and eliminate or control work-related hazards and risks, and to implement the OSH-MS. To this end, training programmes should cover all members of the organization, as appropriate, be conducted by 
competent persons, provide effective and timely initial and refresher training at appropriate intervals, include participants' evaluation of their comprehension and retention of the training, and be reviewed periodically. The review should include the safety and health committee, where it exists, and the training programmes, modified as necessary to ensure their relevance and effectiveness. They should be documented, as appropriate and according to the size and nature of activity of the organization. Training should be provided to all participants at no cost and should take place during working hours, if possible. Occupational safety and health management system documentation should be established and maintained, and may cover the $\mathrm{OSH}$ policy and objectives of the organization, the allocated key OSH management roles and responsibilities for the implementation of the OSH-MS, and the significant OSH hazards/risks arising from the organization's activities. It should also include arrangements for their prevention and control, and arrangements, procedures, instructions or other internal documents used within the framework of the OSH management system. The documentation should be periodically reviewed, revised as necessary, communicated and readily accessible to all appropriate or affected members of the organization.

OSH records should be established, managed and maintained locally and according to the needs of the organization. They should be identifiable and traceable, and their retention times should be specified. Workers should have the right to access records relevant to their working environment and health, while respecting the need for confidentiality. OSH documentation may include records arising from the implementation of the OSH-MS, records of work-related injuries, ill health, diseases and incidents and records arising from national laws or regulations dealing with OSH. They may also include the records of workers' exposures, surveillance of the working environment and workers' health, and the results of both active and reactive monitoring (Ibid).

\subsection{Communication}

Arrangements and procedures should be established and maintained for receiving, documenting and responding appropriately to internal and external communications related to $\mathrm{OSH}$. There is a need to ensure that the internal communication of OSH information between relevant levels and functions of the organization, and that the concerns, ideas and inputs of workers and their representatives on OSH matters are received, considered and responded to ( ILO, 2010).

\section{Planning and Implementation}

\subsection{Initial review}

The organization's existing OSH-MS and relevant arrangements should be evaluated by an initial review, as appropriate. In the case where no OSH-MS exists, or if the organization is newly established, the initial review should serve as a basis for establishing an OSH management system. The initial review should be carried out by competent persons, in consultation with workers and/or their representatives, as appropriate. It should identify the current applicable national laws and regulations, national guidelines, tailored guidelines, voluntary programmes and other requirements to which the organization subscribes. It should 
identify, anticipate and assess hazards and risks to safety and health arising from the existing or proposed work environment and work organization, and determine whether planned or existing controls are adequate to eliminate hazards or control risks. It should also analyse the data provided from workers' health surveillance. The result of the initial review should be documented, become the basis for making decisions regarding the implementation of the OSH-MS and provide a baseline from which continual improvement of the organization's OSH-MS can be measured (Ibid).

\subsection{System planning, development and implementation}

The purpose of planning should be to create an OSH-MS that supports as the minimum, compliance with national laws and regulations, the elements of the organization's OSH management system, and continual improvement in OSH performance (ILO, 2011; 2010). Arrangements should be made for adequate and appropriate OSH planning, based on the results of the initial review, subsequent reviews or other available data. These planning arrangements should contribute a clear definition, priority setting and quantification, where appropriate, of the organization's OSH objectives. There should also be a preparation of a plan for achieving each objective, with defined responsibility and clear performance criteria, indicating what is to be done by whom and when the selection of measurement criteria for confirming that the objectives are achieved, and the provision of adequate resources, including human and financial resources and technical support, as appropriate. The OSH planning arrangements of the organization should cover the development and implementation of all the OSH management system elements.

\subsection{Occupational safety and health objectives}

Consistent with the OSH policy and based on the initial or subsequent reviews, measurable OSH objectives should be established, which are specific to the organization, and appropriate to and according to its size and nature of activity. They should also be consistent with the relevant and applicable national laws and regulations, and the technical and business obligations of the organization with regard to OSH. These should also be focused towards continually improving workers' OSH protection to achieve the best OSH performance. The objectives must be realistic and achievable, documented, and communicated to all relevant functions and levels of the organization and periodically evaluated and if necessary updated.

\section{Hazard prevention}

\subsection{Prevention and control measures}

Hazards and risks to workers' safety and health should be identified and assessed on an ongoing basis. Preventive and protective measures should be implemented in the following order of priority:

(a) eliminate the hazard/risk;

(b) control the hazard/risk at source, through the use of engineering controls or organizational measures;

(c) minimize the hazard/risk by the design of safe work systems, which include administrative control measures; and 
(d) where residual hazards/risks cannot be controlled by collective measures, the employer should provide for appropriate personal protective equipment, including clothing, at no cost, and should implement measures to ensure its use and maintenance (Ibid).

\subsection{Management of change}

The impact on OSH of internal changes (such as those in staffing or due to new processes, working procedures, organizational structures or acquisitions) and of external changes (for example, as a result of amendments of national laws and regulations, organizational mergers, and developments in OSH knowledge and technology) should be evaluated and appropriate preventive steps taken prior to the introduction of changes (ILO, 2011). A workplace hazard identification and risk assessment should be carried out before any modification or introduction of new work methods, materials, processes or machinery. Such assessment should be done in consultation with and involving workers and their representatives, and the safety and health committee, where appropriate. The implementation of a decision to change should ensure that all affected members of the organization are properly informed and trained.

\subsection{Emergency prevention, preparedness and response}

Emergency prevention, preparedness and response arrangements should be established and maintained. These arrangements should identify the potential for accidents and emergency situations, and address the prevention of OSH risks associated with them. The arrangements should be made according to the size and nature of activity of the organization. They should ensure that the necessary information, internal communication and coordination are provided to protect all people in the event of an emergency at the worksite. They should also provide information to, and communication with, the relevant competent authorities, and the neighbourhood and emergency response services. The arrangements must address first-aid and medical assistance, fire fighting and evacuation of all people at the worksite and provide relevant information and training to all members of the organization at all levels, including regular exercises in emergency prevention, preparedness and response procedures. Emergency prevention, preparedness and response arrangements should be established in cooperation with external emergency services and other bodies where applicable.

\subsection{Procurement}

Procedures should be established and maintained to ensure that compliance with safety and health requirements for the organization is identified, evaluated and incorporated into purchasing and leasing specifications. National laws and regulations, and the organization's own OSH requirements are identified prior to the procurement of goods and services and arrangements are made to achieve conformance to the requirements prior to their use.

\subsection{Contracting}

Arrangements should be established and maintained for ensuring that the organization's safety and health requirements, or at least the equivalent, are applied to contractors and their workers. Arrangements for contractors working on site should include OSH criteria in 
procedures for evaluating and selecting contractors. They should establish effective ongoing communication and coordination between appropriate levels of the organization and the contractor prior to commencing work. There is also a need to provide relevant workplace safety and health hazard awareness and training to contractors or their workers prior to commencing work and as work progresses, as necessary. Equally important is the need to regularly monitor OSH performance of contractor activities on site, and to ensure that on-site $\mathrm{OSH}$ procedures and arrangements are followed by the contractor(s).

\section{Evaluation}

\subsection{Performance monitoring and measurement}

Procedures to monitor, measure and record OSH performance on a regular basis should be developed, established and periodically reviewed. Responsibility, accountability and authority for monitoring at different levels in the management structure should be allocated (Ibid). The selection of performance indicators should be according to the size and nature of activity of the organization and the $\mathrm{OSH}$ objectives. Both qualitative and quantitative measures appropriate to the needs of the organization should be considered (Alli, 2001). These should be based on the organization's identified hazards and risks, the commitments in the OSH policy and the OSH objectives, and support the organization's evaluation process, including the management review.

Performance monitoring and measurement should be used as a means of determining the extent to which OSH policy and objectives are being implemented and risks are controlled. They should include both active and reactive monitoring, and not be based only upon work related injury, ill health, disease and incident statistics; and be recorded. Monitoring should provide feedback on $\mathrm{OSH}$ performance, information to determine whether the day-to-day arrangements for hazard and risk identification, prevention and control are in place and operating effectively (Ibid). They should also provide the basis for decisions about improvement in hazard identification and risk control, and the OSH-MS (ILO, 2010). Active monitoring should contain the elements necessary to have a proactive system and should include monitoring of the achievement of specific plans, established performance criteria and objectives. The systematic inspection of work systems, premises, plant and equipment, surveillance of the working environment, including work organization, surveillance of workers' health, where appropriate, through suitable medical monitoring or follow-up of workers for early detection of signs and symptoms of harm to health in order to determine the effectiveness of prevention and control measures, and compliance with applicable national laws and regulations, collective agreements should be enhanced. Other commitments on OSH to which the organization subscribes should also not be ignored. Reactive monitoring should include the identification, reporting and investigation of work-related injuries, ill health (including monitoring of aggregate sickness absence records), diseases and incidents, other losses, such as damage to property, deficient safety and health performance, and OSH-MS failures, and workers' rehabilitation and health-restoration programmes.

11.2 Investigation of work-related injuries, ill health, diseases and incidents, and their impact 
The investigation of the origin and underlying causes of work-related injuries, ill health, diseases and incidents should identify any failures in the OSH-MS and should be documented. Such investigations should be carried out by competent persons, with the appropriate participation of workers and their representatives. The results of such investigations should be communicated to the safety and health committee, where it exists, and the committee should make appropriate recommendations. The results of investigations, in addition to any recommendations from the safety and health committee, should be communicated to appropriate persons for corrective action, included in the management review and considered for continual improvement activities. The corrective action resulting from such investigations should be implemented in order to avoid repetition of work-related injuries, ill health, diseases and incidents. Reports produced by external investigative agencies, such as inspectorates and social insurance institutions, should be acted upon in the same manner as internal investigations, taking into account issues of confidentiality (Ibid).

\section{Audit}

Arrangements to conduct periodic audits are to be established in order to determine whether the OSH management system and its elements are in place, adequate, and effective in protecting the safety and health of workers and preventing incidents (ILO, 2011, 2010). An audit policy and programme should be developed, which includes a designation of auditor competency, the audit scope, the frequency of audits, audit methodology and reporting. The audit includes an evaluation of the organization's OSH management system elements or a subset of these, as appropriate. The audit should cover OSH policy, worker participation, responsibility and accountability, competence and training, OSH management system documentation, communication, and system planning. It should also cover development and implementation, prevention and control measures, management of change, emergency prevention, preparedness and response, procurement, contracting, performance monitoring and measurement, and investigation of work-related injuries, ill health, diseases and incidents, and their impact on safety and health performance. The audit should also include management review, preventive and corrective action, continual improvement and any other audit criteria or elements that may be appropriate. The audit conclusion should determine whether the implemented OSH-MS elements or a subset of these are effective in meeting the organization's $\mathrm{OSH}$ policy and objectives, in promoting full worker participation, and respond to the results of OSH performance evaluation and previous audits. They should also enable the organization to achieve compliance with relevant national laws and regulations, and fulfil the goals of continual improvement and best OSH practice. Audits should be conducted by competent persons internal or external to the organization who are independent of the activity being audited. The audit results and audit conclusions should be communicated to those responsible for corrective action. Consultation on selection of the auditor and all stages of the workplace audit, including analysis of results, are subject to worker participation, as appropriate.

\section{Management review}

It should evaluate the overall strategy of the OSH-MS to determine whether it meets planned 
performance objectives, evaluate the OSH-MS's ability to meet the overall needs of the organization and its stakeholders, including its workers and the regulatory authorities. Management review should evaluate the need for changes to the OSH-MS, including OSH policy and objectives. It should also identify what action is necessary to remedy any deficiencies in a timely manner, including adaptations of other aspects of the organization's management structure and performance measurement. Review must provide the feedback direction, including the determination of priorities, for meaningful planning and continual improvement. It should also evaluate progress towards the organization's OSH objectives and corrective action, activities and evaluate the effectiveness of follow-up actions from earlier management reviews (Ibid).

\subsection{The frequency and scope of periodic reviews}

The frequency and scope of periodic reviews of the OHS-MS, by the employer or the most senior accountable person should be defined according to the organization's needs and conditions (ILO, 2011). The management review should consider the results of work-related injuries, ill health, diseases and incident investigations, performance monitoring and measurement, and audit activities, it should also consider additional internal and external inputs as well as changes, including organizational changes that could affect the OSH-MS. The findings of the management review should be recorded and formally communicated to the persons responsible for the relevant element(s) of the OSH-MS so that they may take appropriate action, and the safety and health committee, workers and their representatives.

\section{Action for improvement}

\subsection{Preventive and corrective action}

Arrangements should be established and maintained for preventive and corrective action resulting from $\mathrm{OSH}$ management system performance monitoring and measurement, OSH-MS audits and management reviews. These arrangements should include identifying and analysing the root causes of any non-conformities with relevant OSH regulations and/or OSH-MS arrangements and initiating, planning, implementing, checking the effectiveness of and documenting corrective and preventive action, including changes to the OSH-MS itself. When the evaluation of the OSH-MS or other sources show those preventive and protective measures for hazards and risks are inadequate or likely to become inadequate, the measures should be addressed according to the recognized hierarchy of prevention and control measures, and completed and documented, as appropriate and in a timely manner.

\subsection{Continual improvement}

Arrangements should be established and maintained for the continual improvement of the relevant elements of the OSH-MS and the system as a whole. These arrangements should take into account the OSH objectives of the organization, the results of hazard and risk identifications and assessments, the results of performance monitoring and measurements, the investigation of work-related injuries, diseases, ill health and incidents, and the results and recommendations of audits. They should also take into account the outcomes of the management review, the recommendations for improvement from all members of the 
organization, including the safety and health committee, where it exists, changes in national laws and regulations, voluntary programmes and collective agreements. Also to be taken into account is new relevant information and the results of health protection and promotion programmes. The safety and health processes and performance of the organization should be compared with others in order to improve health and safety performance (Ibid).

\section{Occupational health and safety management in Zimbabwe}

\subsection{Regulatory Framework}

In Zimbabwe, occupational health and safety laws that are applicable to all employers and employees across sectors are enshrined within the Labour Act, Chapter 28.01, and the National Social Security Authority (NSSA) (Accident Prevention) (Workers Compensation Scheme) Notice No. 68 of 1990 (Mywage, 2011). At a secondary level, there is the Protection from Smoking (Public Health) (Control of Tobacco) Regulations S.I.264 of 2002 that prohibits smoking in enclosed public places including workplaces and the Labour Relations (HIV and AIDS) regulations S.I.202 of 1998 which prohibits discrimination on the ground of AIDS/HIV status, including prohibition of mandatory testing for HIV as a precondition of employment, the duty to respect the confidentiality of HIV status of employees, the provision of protective clothing and other safety devices to prevent the spread of AIDS/HIV at the workplace, including mandatory education and information sharing programmes. Part 2 of the Labour Act, Chapter 28.01 states that no employer shall require any employee to work under any conditions or situations which are below those prescribed by law or by the conventional practice of the occupation for the protection of such employee's health or safety. The NSSA (Accident Prevention) (Workers Compensation Scheme) Notice No. 68 of 1990 is aimed at creating an awareness of, and promoting health and safety at all places of work. It is also aimed at encouraging the adoption of health and safety legislation through factory and machinery inspection (Mywage, 2011). There are also sectoral occupational health and safety laws. These are laws specific to a particular sector whose objective is to supplement the general laws. These laws cover the mining, industry and agricultural sectors.

Within the mining sector, there are provisions for workplace safety which are awarded under the Mines and Minerals Act, Chapter 21:05 and its regulations which include the Mining (Management \& Safety) Regulations S.I 109 of 1990, and the Mining (Health \& Sanitation) Regulations S.I. 185 of 1995 . The main pieces of legislation covering industry are the Pneumoconiosis Act (Chapter 15; 08) and the Factories and Works Act, Chapter 14.08 and its regulations which include the Factories and Works (General) Regulations S.I 263 of 1976, Factories and Works (Registration and Control of Factories) Regulations S.I 262 of 1976, and the Factories and Works (Machinery) Regulations S.I 302 of 1976. They also include the Factories and Works (Electrical) Regulations S.I 304 of 1976, the Factories and Works (Building, structural and Excavation Work) Regulations S.I 264 of 1976, and the Factories and Works (Elevator and Escalator) Regulations S.I 263 of 1976. There are no specific health and safety laws for the agricultural sector. However, the Environmental Management Act, (Chapter 20:27) provides that every worker has a right to work in an environment that does not endanger his or her safety. The Act and its regulations also control usage, storage, labelling and disposal 
of hazardous substances and articles. The collective bargaining agreement for the agriculture industry S.I 323 of 1993 requires employers to provide their employees with appropriate protective clothing and such devices to protect them from harmful substances (Ibid).

\subsection{Institutional framework}

Occupational health and safety management in Zimbabwe is pursued through the International Labour Organization (ILO)'s Zimbabwe Office, the Ministry of Public Service Labour and Social Welfare, and the National Social Security Authority (NASSA) (Government of Zimbabwe, 2010, NASSA, 2012, ZCTU, 2002). They are also implemented through the Zimbabwe Occupational Health and Safety Council (ZOHSC), which comprises government (the ministry and NASSA), employers and labour unions. It is worth noting that the Employers' Confederation of Zimbabwe (EMCOZ) represents employers, whilst employees through their individual trade unions are represented by Zimbabwe Congress of Trade Union (ZCTU), or the Zimbabwe Federation of Trade Union (ZFTU), the two mother bodies of the labour movement in Zimbabwe (Ibid).

\subsubsection{International Labour Organization (ILO) Zimbabwe Office}

The ILO Country Office for Zimbabwe (ILO CO Harare) delivers on its mandate through the Zimbabwe Decent Work Country Programme (ZDWCP) which supports the Government of Zimbabwe and its Social Partners (Employers and Workers' Organizations) in promoting rights at work, harnessing decent employment opportunities, enhancing social protection and strengthening social dialogue in the world of work (ILO, 2012). The ILO CO Harare, in close collaboration with other ILO Departments (Decent Work Team in Pretoria, Regional Office for Africa in Addis Ababa, The International Training Centre in Turin and Headquarters in Geneva) is assisting Zimbabwe to implement programmes that address these four priorities through technical advisory support on policies, technical cooperation projects and activities, studies and research for evidence based decisions and capacity building interventions. It is within this office that occupational health and safety interventions, such as the OHS-MS are adapted to the national level, from the global and regional level. It is also worth noting that Zimbabwe has ratified ILO conventions on occupational health and safety. Amongst these include C155-Occupational Safety and Health Convention, 1981(No. 155) which was ratified on the $9^{\text {th }}$ of April 2003, and C161-Occupational Health Services Convention, 1985 (No.161) which was ratified on 9 April 2003. The country is also currently formulating the next ZDWCP for 2012 - 2015 from which more plans, policies, programmes and projects on occupational safety health and safety are expected to be initiated (Ibid).

\subsubsection{Ministry of Labour and Social Welfare}

The ministry is the arm of the state which is acting in partnership with the ILO in occupational health and safety governance (Government of Zimbabwe, 2010). The mission of the Ministry of Labour and Social Welfare is to promote fair labour practices and enhanced labour productivity, self reliance and social protection and the efficient, effective and accountable operation of the Public Service in Zimbabwe. The objective is to make the 
greatest possible contribution to the social and economic well being of Zimbabwe. It also seeks to provide assistance and support to the vulnerable through the development and implementation of effective policies and legal instruments, professional social work and training in order to promote self reliance and social security. The ministry formulates and implements national plans, policies, programmes and projects on occupational health and safety through the National Social Security Authority (NASSA) (Ibid).

\subsubsection{National Social Security Authority (NASSA)}

The National Social Security Authority (NSSA) was created by an act of Parliament, namely the National Social Security Authority Act (Chapter 17:04) of 1989 (NASSA, 2012). This act empowers the Minister of Labour and Social Welfare to establish social security schemes for the provision of benefits to or in respect of all employees as may be specified in the notice and may in the like manner amend or abolish any such scheme. It is a statutory corporate body tasked by the Government to provide social security. The provision of social security can be defined as instituting public policy measures intended to protect an individual in life situations or conditions in which his/her livelihood and well being may be threatened, such as those engendered by sickness, workplace injuries, unemployment, invalidity, old age, retirement and death. It is based on the principle of social solidarity and pooling of resources and risks, involving drawing of savings from periods of employment, earnings and good health to provide for periods of unemployment, old age, invalidity and death. At the moment NSSA is administering two schemes namely the Pension and Other Benefits Scheme and the Accident Prevention and Workers' Compensation Scheme (Ibid).

NSSA is managed by a tripartite board constituting equal representation from Government, employer representatives (EMCOZ) and employees representatives (ZCTU and ZFTU) (International Organization of Employers, 2011). The administration is headed by the General Manager assisted by six directors of operational divisions, amongst which include occupational safety and health. The Authority's operations are at head office in Harare and six regional offices in Harare, Bulawayo, Gweru, Mutare, Masvingo and Chinhoyi, and ten sub-offices in Bindura, Gwanda, Chiredzi, Kwekwe, Hwange, Kadoma, Marondera, Chipinge, Rusape and Kariba. NASSA has an Occupational Safety and Health Division which exists to promote occupational safety and health in Zimbabwe through the establishment and maintenance of an effective occupational safety and health culture based on comprehensive accident and ill health preventive systems at all workplaces (NASSA, 2012). The Division has four departments namely Factory Inspectorate, Occupational Health Services, OSH Promotions and Training, and Research and Development. The OSH Director also reports to a tripartite organization called the Zimbabwe Occupational Health and Safety Council (ZOHSC) which comprises government, employers and labour unions (Ibid). It is within this framework that sector wide plans, policies, programmes and projects such as the OSH-MS are managed.

\subsubsection{Zimbabwe Occupational Health and Safety Council (ZOHSC)}

It comprises government (the ministry and NASSA), employers and labour unions 
(International Organization of Employers, 2011; ZOHSC, 1997). It provides a platform upon which occupational health and safety management plans, policies, programmes and projects deliberated and translated into sector, industry and individual organizational interventions. EMCOZ represents employers, whilst employees through their individual trade unions are represented by Zimbabwe Congress of Trade Union (ZCTU), or the Zimbabwe Federation of Trade Union (ZFTU), the two mother bodies of the labour movement in Zimbabwe (Ibid). The council provides a link between government and individual organizations for the systematic formulation, implementation, evaluation and review of occupational safety and health plans, policies, programmes and projects emanating from the national, international and organizational levels. It is this forum which provides a platform upon which the OSH-MS may be implemented in Zimbabwe.

\section{Conclusions}

The discussion was on the Occupational Health and Safety Management System (OHS-MS), formulated by the International Labour Organization (ILO) to facilitate the formulation, implementation and evaluation of interventions at a national policy, sector and organizational level in all countries. It also focused on Zimbabwe's occupational health and safety policy, regulatory and institutional framework. The ILO's OSH-MS 2001 was developed to provide a unique international model, compatible with other management system standards and guides, towards promoting occupational health and safety. It was concluded that the OSH-MS includes policy, organizing, planning and Implementation, evaluation, and action for Improvement. Although other occupational health and safety models use different terminology, the process and workflow for occupational health and safety management systems is always the same. It entails the establishment, within policy statements, of what the requirements are for the organization in terms of resources, defining management commitment and defining occupational safety and health targets. It also involves determining how the organization is structured, where the responsibilities and accountabilities are defined, who reports to who and the allocation of responsibilities. It was also concluded that planning and implementation, in this management system, involve determining the legislation and standards which apply to an organization, what OSH objectives are defined and how these are reviewed, hazard prevention and the assessment, and management of risk procedures and processes. The system also involves determining how the occupational safety and health intervention performance are measured and assessed, the processes for the reporting of accidents and incidents and for the investigation of accidents and the internal and external audit processes in place to review the system. This lays a platform upon which action for continual improvement may be pursued, through determining how the preventative and corrective actions are managed and the processes in place to ensure the continual improvement process. It was also concluded that the management system is not legally binding and not intended to replace national laws, regulations and accepted standards. It reflects ILO values such as tripartism and relevant international standards including the Occupational Safety and Health Convention, 1981 (No. 155) and the Occupational Health Services Convention, 1985 (No. 161). 
In Zimbabwe, it was concluded that occupational health and safety laws that are applicable to all employers and employees across sectors are enshrined within the Labour Act, Chapter 28.01, and the National Social Security Authority (NSSA) (Accident Prevention) (Workers Compensation Scheme) Notice No. 68 of 1990. At a secondary level, there is the Protection from Smoking (Public Health) (Control of Tobacco) Regulations S.I.264 of 2002 that prohibits smoking in enclosed public places including workplaces and the Labour Relations (HIV and AIDS) regulations S.I.202 of 1998 which prohibits discrimination on the ground of AIDS/HIV status, including prohibition of mandatory testing for HIV as a precondition of employment, the duty to respect the confidentiality of HIV status of employees, the provision of protective clothing and other safety devices to prevent the spread of AIDS/HIV at the workplace, including mandatory education and information sharing programmes. It was also concluded that occupational health and safety management in Zimbabwe is pursued through the International Labour Organization (ILO)'s Zimbabwe Office, the Ministry of Labour and Social Welfare, the National Social Security Authority (NASSA), and the Zimbabwe Occupational Health and Safety Council (ZOHSC), which comprises government (the ministry and NASSA), employers and labour unions. The ILO Country Office for Zimbabwe (ILO CO Harare) delivers on its mandate through the Zimbabwe Decent Work Country Programme (ZDWCP) which supports the Government of Zimbabwe and its Social Partners (Employers and Workers' Organizations) in promoting rights at work, harnessing decent employment opportunities, enhancing social protection and strengthening social dialogue in the world of work.

On the other hand, it was concluded that the Ministry of Labour and Social Welfare formulates and implements national plans, policies, programmes and projects on occupational health and safety through the National Social Security Authority (NASSA). NSSA is managed by a tripartite board constituting equal representation from Government, employer representatives (EMCOZ) and employees representatives (ZCTU and ZFTU). It has an Occupational Safety and Health Division which exists to promote occupational safety and health in Zimbabwe through its four departments namely Factory Inspectorate, Occupational Health Services, OSH Promotions and Training, and Research and Development. Sector wide plans, policies, programmes and projects such as the OSH-MS are managed at this level. It was also concluded that the Zimbabwe Occupational Health and Safety Council (ZOHSC), which comprises government (the ministry and NASSA), employers and labour unions provides a platform upon which occupational health and safety management plans, policies, programmes and projects deliberated and translated into sector, industry and individual organizational interventions. In this council, EMCOZ represents employers, whilst employees through their individual trade unions are represented by Zimbabwe Congress of Trade Union (ZCTU), or the Zimbabwe Federation of Trade Union (ZFTU), the two mother bodies of the labour movement in Zimbabwe. It was concluded that this forum provides a platform upon which the OSH-MS may be implemented in Zimbabwe.

\section{Recommendations}

From the discussion, it is recommended that Zimbabwe fully adopts the OHS-MS in all 


\section{Macrothink

sectors, industries and organizations in an adaptive manner. This emanates from the fact that the management system provides a platform upon which occupational health and safety plans, policies, programmes and projects may be systematically managed and improved on a continual basis. There is also a need to continue engaging in systematic capacity building at a national, sectoral, industrial and organizational level to enhance effective, efficient and adaptive implementation of this tool. Continuous interaction and engagement between the ILO, Ministry of Labour and Social Welfare, EMCOZ, ZCTU and ZFTU is also recommended. There is also a need to continue on this common purpose for the realization of the highest standards of occupational health and safety in Zimbabwe. 


\section{References}

Alli, B. (2001). Fundamental Principles of Occupational Health and Safety. International Labour Office, Geneva

Government of Zimbabwe, (2010). Ministry of Public Service, Labour and Social Welfare. www.pslsw.gov.zw Accessed 26 July 2012

ILO, (2012). Country Office Zimbabwe: http://www.ilo.org/public/english/region/afpro/harare/ Accessed 24 July 2012

ILO, (2010). Guidelines on Occupational Safety and Health Management Systems(ILO-OSH 2001). SafeWork, ILO Geneva

http://www.ilo.org/wcmsp5/groups/public/---ed_protect/---protrav/---safework/documents/pu blication/wcms_110496.pdf Accessed 22 July 2012

ILO, (2011). OSH Management System; A tool for Continual Improvement. ILO, Turin

International Organization of Employers, (2011). Employers Confederation of Zimbabwe. http://www.ioe-emp.org/en/ioe-members/index.htm Accessed 25 July 2012

Mywage Zimbabwe, (2011). Health and Safety Laws. http://www.mywage.org/zimbabwe/main/decent-work-check/health-and-safety-laws

Accessed 22 July 2012

National Social Security Authority, (2012). Occupational Health and Safety (OHS). http://www.nssa.org.zw/pages/ohs.htm Accessed 23 July 2012

Zimbabwe Congress of Trade Unions (2002). Survey of Occupational Health Practices at workplace level. Mimeo Report, Harare

Zimbabwe Occupational Health and Safety Council (ZOHSC)/NSSA, (1997). Comprehensive analysis of health and safety management in Zimbabwe-ZOHSC assessments in 1997. Mimeo Report, Harare 